\title{
LAS LECHUGAS Y LA ETIMOLOGÍA DE AMAINAR
}

\author{
Germán Colón Doménech. \\ Universidad de Basilea.
}

\section{El INSólito amainar.}

El origen del verbo amainar 'bajar las velas (de una embarcación)' es obscuro y los romanistas no se ponen de acuerdo sobre el centro desde donde irradió este vocablo. No hay poligénesis, en ello todo el mundo coincide. Pero las preferencias de unos $\mathrm{y}$ otros se inclinan por el dominio catalán (o catalano-occitano), de un lado, y por el reino de las Dos Sicilias, de otro. En el primer supuesto vendría de un AD+MANSIONARE $>$ amainar, mientras que *INVAGINARE sería la base de un napolitano ammaienare.

Huelga decir, ante este ejemplar caso de jugueteo fonético-combinatorio, que, cuando no se tiene en cuenta la historia léxica asentada en textos fehacientes, todo resulta posible en el campo etimológico.

El acopio de una documentación extensa de varias lenguas románicas me ha llevado a una conclusión diferente de esa doble proposición. Pero no voy ahora, en esta nótula, a entrar en el debate. Dejo el asunto para una próxima ocasión. Hoy quisiera sólo aclarar lo que hay de veras en un pasaje del tratado de Macer, De herbis ${ }^{1}$, que ofrece el manuscrito de Valencia (traducción catalana del siglo $\mathrm{xv}$ ), en donde se ha señalado la presencia de amainar. En la edición del Dr. Faustino Barberà, que viene reproducido por J. Ribelles Comin, leemos lo siguiente acerca de las lechugas:

"De les letuges. Sapies que les letuges son fredes | e vmydes e han aquesta vyrtut que si son menjades poden amainar les grans calors | o posades sobre la cremor val hi | e sapies que profita molt al ventre si son menjades que

\footnotetext{
1. Macer, Aemilius, De viribus herbarwom. No existe edición crítica moderna de este tratado, que tanto influjo tuvo durante siglos en Europa.
} 
non sien lauades a la sement de la letugua | a aquel qui la menja fer la sommjar sompnjs vans" 2 .

Este pasaje se lo indiqué a W. von Wartburg en 1959, cuando en sus oficinas se preparaba el artículo mansio ${ }^{3}, \mathrm{y}$ desde entonces ha ido rodando por la discusión etimológica, la cual en estos momentos se inclina a favor de la tesis catalana 4 . Lamento haber contribuido a la confusión general, aunque no fui el primero en revelar la existencia del vocablo. Fue el $D C V B$ (1. ${ }^{\text {a }}$ ed., 1930. s. v. amaynar) quien lo tomó de la mencionada bibliografia de Ribelles Comín. De ahí pasó al DCELC, s. v. amainar (I, 1954, pág. 179): “en catalán se halla amainar ya en textos del s. xv, y en uno de ellos aparece en la ac. figurada de 'mitigar (el calor)' (vid. Alcover)".

Mientras tanto el erudito Lluís Faraudo de Saint-Germain publicaba una edición del Macer catalán basada en el manuscrito de la BN de París, en donde el paso en cuestión era:

“De latugues. Letuges, sàpies que són fredes e homides; e han aquesta virtut: que si són menjades, poden asuavar les gran (sic) calors, ho posades picades sobre la cremor.

Item, sàpies que profiten molt al ventre, si són menjades que no sien lavades.

Item, la sement de la letuga, aquell qi la menja, fer-l'à de nuyt somiar sompnis vans" s.

Ahora el aspecto cambiaba, y en mi primera recensión al Diccionario crítico etimológico de la lengua castellana de J. Corominas a propósito del verbo amainar matizaba así el problema: "El ejemplo catalán del siglo xv, que trae Alcover-Moll, donde amainar significa 'mitigar (el calor)', me parece dudoso. Procede de la versión del De Herbis de Macer: «letugues... poden amainar les grans calors ; así en el texto cuatrocentista de Valencia publicado por el médico $\mathrm{F}$. Barberà (la edición no es muy cuidada); pero en el manuscrito de París, publicado recientemente por Lluís Faraudo de Saint-Germain (Estudis Romànics, V, pág. 23), hallamos: «letuges ... poden asuavar les grans calors». Creo que ésta es la buena lección, y lo mismo debe

2 J. Ribelles Comín, Bibliografía de la lengua valenciana, I, Madrid, 1915, pág. 383b.

3 Véase la larga nota 111, en $F E W$, VI-1, pág. 253. El redactor del artículo mansio del $F E W$ fue Kurt Baldinger, pero W. von Wartburg quiso intervenir, redactando la nota citada, a propósito de amainar, lexema que él anteriormente había colocado bajo el artículo *INVAginare (cf. op. cit., IV, pág. 787a).

- Por ejemplo, véase Maria Alexandra Tavares Carbonell Pico, A terminologia naval portuguesa anterior a 1460, Lisboa, 1963, pág. 483.

s Lluís Faraudo de Saint-Germain, "Una versió catalana del Libre de les herbes de Macer", Estudis Romdnics, 1955-1956, V, págs. 23-24. 
de decir el ms. valenciano; por lo demás es raro que se escribiese amainar en vez de amaynar" ".

Francesc de B. Moll se hacia eco de mi observación, en la refundición de los primeros tomos del Diccionari català-valencià-balear, y se mostraba escéptico sobre la validez del testimonio valenciano: "Es molt dubtós que en aquest text de Macer existeixi realment el mot amainar; segons Germà Colón en $Z R P h$, LXXVIII, 69-70, es tracta d'una falsa lectura per asuauar, que és la forma que apareix en el text de Macer publicat per Faraudo"?

\section{La lectura del ManUSCRito.}

Por el contrario, en este punto el Sr. Corominas en el DECH (1980) no ha cambiado de doctrina y sigue manejando el tal amainar del siglo $\mathrm{xv}$, con la presunta acepción figurada de 'mitigar (el calor)'. No le conviene al lexicógrafo barcelonés variar su posición, pues la creencia de que todo viene del catalán se exacerba cada vez más, y en el DECat pasa a desautorizar a beneméritos editores como a Ll. Faraudo, a F. A. Ugolini y a M. de Riquer porque "ninguno de los tres conoce los trabajos sobre la antigüedad, la etimologia y la catalanidad básica de amainar" 8 . No sigo traduciendo porque luego vienen valoraciones despectivas en las que el autor es maestro indiscutible. Lo curioso es que ahi mismo reproche a Faraudo que no haya tomado en consideración ("tampoc l'ha presa en seriosa consideració") la lección amainar del otro manuscrito de Macer, cuando Faraudo se limitó a editar el códice de Paris y no pretendió presentar un texto crítico con variantes 9 .

Sigue don Joan con sus brillantes varapalos, y llega el momento en que me toca recibirlos a mi : tras afirmar que unas veces acierto y otras me equivoco [uno no es Dios, me digo], viene la ática sal: "més d’un cop naufraga

- G. Colón, "El \&Diccionario crítico etimológico de la lengua castellanas de Corominas. Notas de lexicografia y etimología hispánicas", ZRPh, LXXVIII, 1962, páginas $69-70$.

7 DCVB, I, Palma de Mallorca, 1968, pág. 595b.

s Diccionari critic $i$ complementari de la llengua catalana (= DECH), Barcelona, Curial, 1980, I, pág. 252a: "cap dels tres no coneixen els treballs sobre l'antiguitat, l'etimologia i la catalanitat bàsica d'amainar".

9 Añade que no puede ahora entrar en la cuestión de establecer "quina és la lliçó més certa" (ib., líneas 19-20). Claro está, puesto que desconoce los textos y los cita de segunda o tercera mano; si no, véase en ese diccionario el artículo bolomaga (especialmente nota 1), en donde, a propósito de nuestro Macer, sólo se aduce el pasaje del manuscrito valenciano (que trae el $D C V B$, s. v. bolmaga ...) y se pasa por alto el bolmoja del Macer de la BN de París: "Atzaró o bolmoja" (cf. ed. Faraudo, Estudis Romanics, V, pág. 34 , fol. $39 d$ ), del que se tiene una indirecta sombra. 
quan els textos nàutics no li ctiren un caps" 10 . Es verdad que siempre me apoyo en la documentación: es más, procuro prescindir de la imaginación, cuando va a solas, para no escribir demasiadas inanidades. Si yo tuviera las mismas buenas intenciones que mi intemperante fustigador, le replicaria que, si a mi los textos me ayudan, él necesitaria fijarse más en ellos y amarrar su capacidad de invención, con harta frecuencia desprovista de asidero documental. Pero no voy a dejarme llevar por la senda de la polémica y presentaré el texto que nos ocupa, que me ha costado mucho conseguir ". Se trata del Ms. 216, fol. 35 v. ${ }^{\circ}$, de la "Biblioteca universitària de València", que dice asi ${ }^{12}$ :

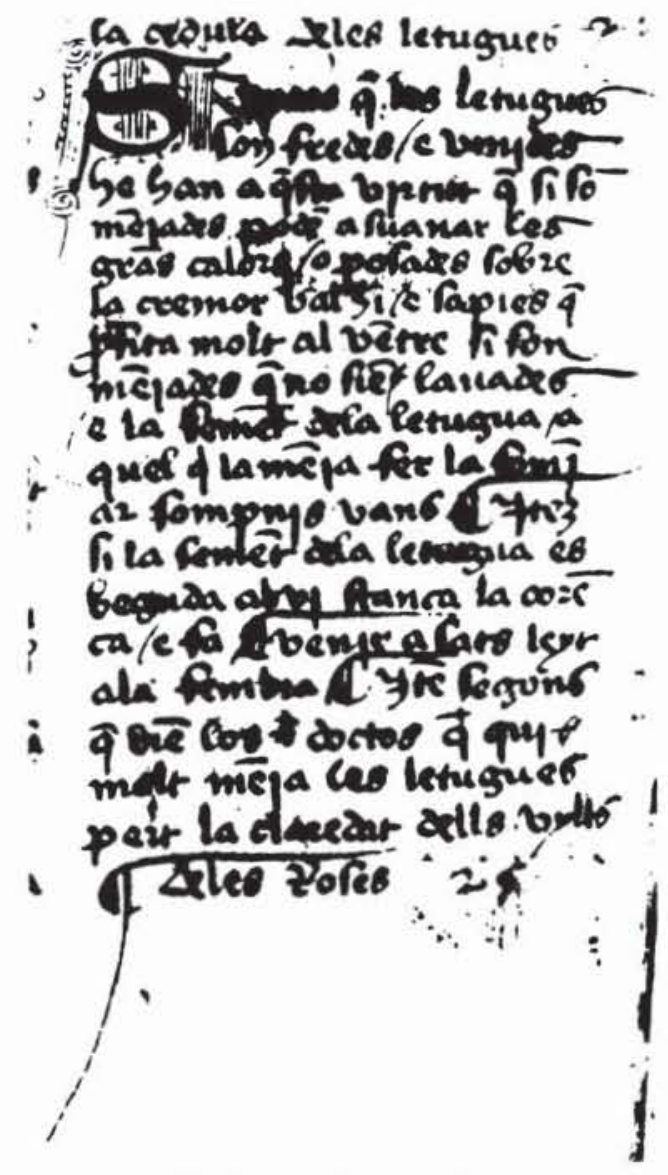

València, Biblioteca Universitària, ms. 216, fol. 35 v. ${ }^{\circ}$

10 "Más de una vez naufraga cuando los textos náuticos no le «echan un cabo»" (ibidem, pág. 253b).

11 Agradezco a mi buen amigo y colega Albert G. Hauf, catedrático de la Universidad de Valencia, que me haya proporcionado la fotocopia del manuscrito, tras la que anduve durante tanto tiempo.

is Sigo en la transcripción las normas de la colección "Els Nostres Clàssics", pero señalo entre paréntesis algunas lecturas paleográficas. 
"De les letugues. Sàpies que les letuges són fredes e umides («umjdess). He han aquesta virtut: que si són menjades, poden arwavar («asuauars) les grans calors, o posades sobre la cremor val hi. E sàpies que profita molt al ventre, si són menjades que no sien lavades. E la sement de le letugua a.quel qui la menja fer l'à somniar sompnis vans" ${ }^{13}$.

La lección de los manuscritos de Valencia y de París es, pues, la misma : asuauar, esto es literalmente 'suavizar' (derivado de suau 'suave'). La transcripción amainar es un error. El lector puede comprobar la lectura en la adjunta reproducción fotográfica del citado folio del manuscrito valenciano.

Una vez aclarado nuestro pequeño problema y suprimido un fantasma lexicográfico, podremos dedicarnos a estudiar la etimología románica de amainar. Prometo volver con muchos textos, unos conocidos, y varios más, desconocidos. Y adelanto que, de entre los primeros, la interpretación no siempre coincide con la apresurada del DECat.

\section{Los SUeÑos Y LA Lechuga.}

Ya que queda atrás el fantasma de marras, veamos todavía una friolera de enigma que también nos brinda la lechuga: los escritos catalanes, en la última frase transcrita, aseveran que la simiente de ésa provoca en quien la come sueños vanos. Estas propiedades alucinógenas no se dan en el texto latino de Macer, conservado en la Real Colegiata de San Isidoro de León; al contrario, dicha semilla ahuyenta esos vanos sueños. El pasaje correspondiente reza asi :

"De lectuca herba. XX.

Frigida lactuce vis constat et humida valde: Unde potest nimios hec mansa lauare colores (sic) ${ }^{14}$. i Et prestabit idem superaddas si bene tritam. | Utilis est stomacho somnum dat emolit et alvuum | omnibus hiis melius prodest decocta comesta. | Lactuce semen compescit somnia vana" ${ }^{15}$.

13 Una versión aproximada podría ser ésta: De las lechugas. Has de saber que las lechugas son frías y húmedas. Y tienen esta virtud, que si se comen, pueden mitigar los grandes calores y puestas sobre la parte que sufre ardor son eficaces. E sepas que aprovecha(n) mucho al vientre, si se comen sin ser lavadas. Y la simiente de la lechuga a quien la come le hará soñar sueños vanos.

14 La lección lauare colores es muy clara en vez de "leuare calores" del canon. El traductor (véase nota siguiente) no la ha tenido en cuenta y ha seguido la lectura tradicional.

15 Macer floridus. Edición facsimil del herbario-médico medieval de la Real Colegiata de San Isidoro, de León, León, Universidad de León, 1990, fol. c II v. ${ }^{\circ}$ En la traducción de Pedro Cabello de la Torre, que acompaña el facsímil, leemos: "De la lechuga. La fuerza de la lechuga es fría y muy húmeda. Puede esta hierba masticada aliviar los excesivos calores, y actuará lo mismo si la aplicas bien triturada. Es útil al 
Ahi la simiente compescit ('rechaza, ahuyenta') las alucinaciones al que la toma. Estamos, pues, ante una incongruencia en el Macer hispánico: mientras los dos textos catalanes, coincidentes en este punto ${ }^{16}$, traen fer-l'ha somniar somnis vans 'le hará soñar sueños vanos', el manuscrito leonés afirma que esos desvarios vienen rechazados.

Las dos ediciones latinas de Macer más antiguas que se conservan en la Biblioteca Universitaria de Basilea nos proporcionan la solución. El incunable milanés de 1482 dice para la frase final "Lactuce semen compescit sompnia uana" ${ }^{17}$, en concordancia con el Macer de San Isidoro de León. En cambio, el impreso véneto de 1506 se ajusta a la lección de los manuscritos catalanes: "Lactuce semen componit somnia uana" ${ }^{18}$. Es, pues, la tradición textual europea la que ha provocado esta llamativa discrepancia. Algunos pacientes de otrora, al leer estos remedios, debieron de pagar con insomnios las rarezas de una veleidosa recepción o vieron defraudadas sus esperanzas durante la vigilia.

Añadamos, a manera de apéndice, que el texto castellano de Macer, impreso en Granada en 1518, va por otro lado y no habla de sueños inútiles, pero asevera que ese vegetal tiempla el ardor de los humores y ayuda a dormir. He aqui entero el capitulo de las lechugas:

\footnotetext{
"Son las lechugas frias \& humidas \& ligeras de moler \& hazen mucho buena sangre como quier que la hazen fria \& fleumatica \& tiempla el ençendimiento de los humores de los miembros. E señaladamente del estómago. E por ende ayudan bien a dormir : \& valen mucho para el ençendimiento de los malos bafos que suben a la cabeça. Señaladamente sy son colericos: \& son mejores para comer cochas que crudas: como quier que en toda manera son buenas mas quando los hombres quieren quitar algun poco de la su gran frialdad: Deuelas comer cozidas. \& deuense cozer enteras : \& non deuen mucho cozer. \& para comer crudas mejores son las nouezitas que las otras. E las lechugas acrecientan la leche en las tetas de las mugeres. \& por ende es buena vianda para las amas" 10 .
}

\footnotetext{
estómago, atrae el sueño y ablanda el vientre. Para todo esto aprovecha mejor si se la come cocida. Las semillas de la lechuga ahuyentan los sueños vanos e inútiles." (página $\mathrm{xLI}$ ).

16 Prescindo aquí de señalar la relación que guardan entre sí ambos textos así como de su procedencia.

${ }_{17}$ Macri de usibus herbarum liber primus. Antonius Zarotus parmensis impressit Mediolani MCCCCI.XXXII, die. XIX Nouembris, "De latuca".

${ }_{18}$ Macri philosophi de virtutibus herbartem noviter inventus ac impressus. Venetii impressus per Bernardinum Venetum de Vitalibus, MDVI, "De lactvca", [Ci].

${ }_{10}$ Textos y concordancias del "Libro de medecina llamado macer", Granada, Andrés de Burgos, 1518 y 1519, ed. Thomas Capuano, Madison, The Hispanic Seminary of the Medieval Studies, 1991, microficha de la pág. 26 (III, 5). Prescindo de los paréntesis y corchetes del editor, con los que se indican las abreviaturas desarrolladas; para nuestro objetivo no son necesarios. El texto de 1519 es exactamente igual que el del afio anterior.
} 